\title{
Modeling Household Cooking Fuel Energy Choice in Rwanda
}

\author{
Mushinzimana Isaac, Niyonshuti Emmanuel \\ Department of Energy Economics, African Centre of Excellence in Energy for Sustainable Development University of Rwanda, Kigali, \\ Rwanda
}

Email address:

mushinzisaac@gmail.com (M. Isaac), niyency@yahoo.fr (N. Emmanuel)

\section{To cite this article:}

Mushinzimana Isaac, Niyonshuti Emmanuel. Modeling Household Cooking Fuel Energy Choice in Rwanda. American Journal of Modern Energy. Vol. 7, No. 4, 2021, pp. 61-68. doi: 10.11648/j.ajme.20210704.13

Received: March 30, 2021; Accepted: April 29, 2021; Published: August 23, 2021

\begin{abstract}
This investigation applies a multinomial logit procedure to demonstrate decisions of fuel for cooking in Rwanda. The decisions considered are five fundamental cooking fuels: wood, charcoal, gas, lamp oil and generator; Using the Integrated Household Living Condition Surveys from 2010 up to 2017 (EICVs 2010-2017) data, the study identifies the driving forces that underpin and support the household's decision of fuel for cooking and investigates the fundamental factors that decide decision of essential cooking fuel choices in Rwanda. The descriptive results showed the higher dependency on biomass cooking fuel among Rwandan households with 84.55 percent for firewood usage and 12 percent for charcoal usage for cooking and the result multinomial logit revealed that location of living arrangement, home possession, household size, type of marriage, household income level, and type of habitant play significant role in explaining the probability of cooking fuel choices within households. Further the results show that clean energy is bound to be utilized in urban families, where household with high income more often use LPG compare to others. The study also showed that main stream of household in Rwanda depend on more on non-clean energy while cooking, and this is more pronounced in rural households.
\end{abstract}

Keywords: Cooking Fuel, Household Energy Choice, Multinomial Logit

\section{Introduction}

Energy consumption for households is an essential bearing in mind its significance on household welfare and environment. The shape of energy consumption for household designates the welfare state and individual economic development and that of a certain country according to Arowosoge and Faleyimu [1]. The accessibility of the modern and clean energy services is crucial for achievement of sustainable development goals (SDGs) while lack of access to this reliable, affordable, harmless and clean energy is a resilient restriction on human development due to the report of United Nations in 2020 [2]. Switching to modern, efficient and clean cooking fuels is hypothesized to bring about the greatest reduction in the household air pollution as designated by WHO [3], the authors Rehfuess et al. [4] revealed that although clean-burning fuels are effective means for addressing indoor air pollution and their respective health impacts, there are numerous potential factors to be considered for switching to modern and clean cooking fuels including accessibility, cost, information and socio-cultural factors.

The aim of this study is to analyse the factors influencing the cooking fuels choice to switch between traditional and modern clean cooking fuels. Rwandan households are the case of study. However, most of energy utilized in Rwandan families even today is for cooking. Subsequently, a comprehension of cooking energy utilization configurations is predominantly significant in Rwanda according to Ladislas [5].

The smoke resulted from the utilization of wood fuel is consequently unsafe to human wellbeing, particularly to ladies and youngsters who generally do the cooking during home activities (NEPD, 2003). Malinski [6] revealed that besides, around 1.5 million passing consistently from respiratory diseases can be ascribed to the climate, including the impacts of indoor and open air contamination.

According to national institute of statistics [7], fifth integrated household living conditions survey, households in Rwanda spend up to six hours per day for firewood collection 
and up to third of their income for their energy expenditures while National wide almost 82.59 percent of household use wood fuel as their principal source of cooking purposes. Households collect firewood for free from the forest and this is time consuming task. In Rwandan households, despite of modern, clean and less time consuming energy accessibility, we also need to observe other determining factors influencing the household cooking fuel decision option.

Ladislas [5] showed that the use of biomass sometimes refers to non-clean cooking fuels and traditional fuels. It is highly prevalent in Rwanda. In this study we analyse and understand the factors influencing the household choices for cooking energy fuels. We perform this through switching from traditional cooking fuels to modern clean cooking fuels. The setting is particularly relevant to other nations with limited adaptation of modern clean cooking fuels. Our analysis considers the households in both urban and rural areas of Rwanda.

There are studies carried out on investigating the household level determinants affecting the cooking fuel energy choices. Zhang and Hassen [8] Utilize the probit model for household fuel decision for cooking and showed that there is a replacement impact on cost of Liquefied Natural Gas (LNG), coal and fire wood designating that at the point when the cost of LNG builds, the likelihood of picking coal for essential energy for cookery additionally increments. Alem et al. [9] carried out an investigation in metropolitan Ethiopia and showed that fuel costs are significant determining factor for energy decision. Reddy [10] showed that with the expansion in earnings and the increment for cost of fire wood, household would in general move to clean fuel source. Heltberg [11] utilized the probit model and showed that the income is the main driving factor in the household decision of cooking fuel in metropolitan China. Alam and Barnes [12] Showed that as the income expands, family incline toward $\mathrm{LNG}$ as essential fuel for cooking however the likelihood of picking fuel wood and coal as essential fuel for cooking has diminished. Likewise Chambwera and Folmer [13] showed the positive connection among income and energy utilization, with an alternate methodology of expanding income in energy utilization and conclude that there is positive connection among income and family unit interest for marketable fuel.

Saad and Bugaje [14] conducted the study in Nigeria and showed that there is negative connection among income and utilization of biomass on the off chance that the income of family unit builds, the families attempt to substitute biomass fuel by present day fuel energies. Farsi et al. [15] revealed a positive connection between family size and likelihood of picking LPG. Gangopadhyay et al. [16] Revealed that the expansion in size of household which may build the volume cooked and it requires more energy to prepare food is found in the investigation of remote zone of Nigeria.

Ouedraogo [17] Suggests that, in metropolitan Burkina Faso, families with less individuals are twenty-6th times bound to receive LPG and more averse to utilize traditional for cooking. Koswari et al. [18] Carried out the study and showed that apart from traditional cooking energy fuels, LPG and Electricity as modern cooking energy fuels are often taken as better fuels alternatives from healthiness welfares perceptions and efficiency. However in developing nations the families' choice to shift after traditional cooking biomass fuels to modern cooking energy fuels was bounded by some constraints like the cultural, social and economic and environment obstructions.

Van de Kroon et al. [19] have attested the energy stepping stool as the essential model that impacts families' decisions as the change movement from customary cooking energy fuels to cleaner current cooking energy fuels. As indicated by the energy ladder theory by covering the ceteris paribus with an expansion in earnings, families not just devour greater amount of a similar cooking energy fuels yet in addition change to the cleaner present day cooking energy fuel type.

Rahut et al. [20] revealed that it is expected that cleaner modern energy fuels for cooking are typically monetary products while traditional biomass cooking energy fuels are considered as inferior good. From the cited literatures there are limited studies carried out on investigating the driving forces considering the energy preferences and consumer behavioural constraints that influence the choice of cooking energy fuels amongst the clean modern and traditional cooking fuels for family units at disaggregated level in Rwanda.

\section{Materials, Methods and Data}

\subsection{Conceptual Framework}

A household fuel energy decision choice can be clarified by inspecting its fuel choice in a compelled utility improvement structure, where it boosts fuel utility, subject to a bunch of monetary and noneconomic limitations. The family's information on different impacts its fuel decision and fuel replacement choices. This fuel utilization choice is influenced by financial and noneconomic factors. Financial variables may incorporate market cost of fuel, family earnings, and family consumptions and non-monetary elements may incorporate a bunch of household qualities, for example, household size, gender of household head, information, house ownership, kind of abiding, area of habitation, family age, separation to fuel source, and admittance to electric energy according to the author Wickramasinghe conducted study in Sri Lanka [21].

The figure above showed how household's fuel consumption decision is influenced by socioeconomic factors, where household may decide to use traditional cooking fuel energy which are non- cleaned and they damage health and increase pollution within environment also household decided to use cleaned cooking fuel energy which improve health and reduce pollution which lead to increase of general mass welfare which imply that there is the main factors influencing this cooking fuel energy choice according to the authors Ezzati and Kammen[22] carried out the study in Kenya.

This study was centered on pooled cross-sectional survey data 
from Integrated Household Living Conditions Surveys (EICVs) data, conducted by the National Institute of Statistical of Rwanda (NISR) three waves (2010, 2013/14 and 2016/17). The Survey is a broadly agent test study intended to give data on the different parts of household government assistance in Rwanda.
The reviews gathered data from three waves-based household measurably intended to be delegated at both public, rural, urban and provincial levels, empowering the arrangement of dependable appraisals for these levels.

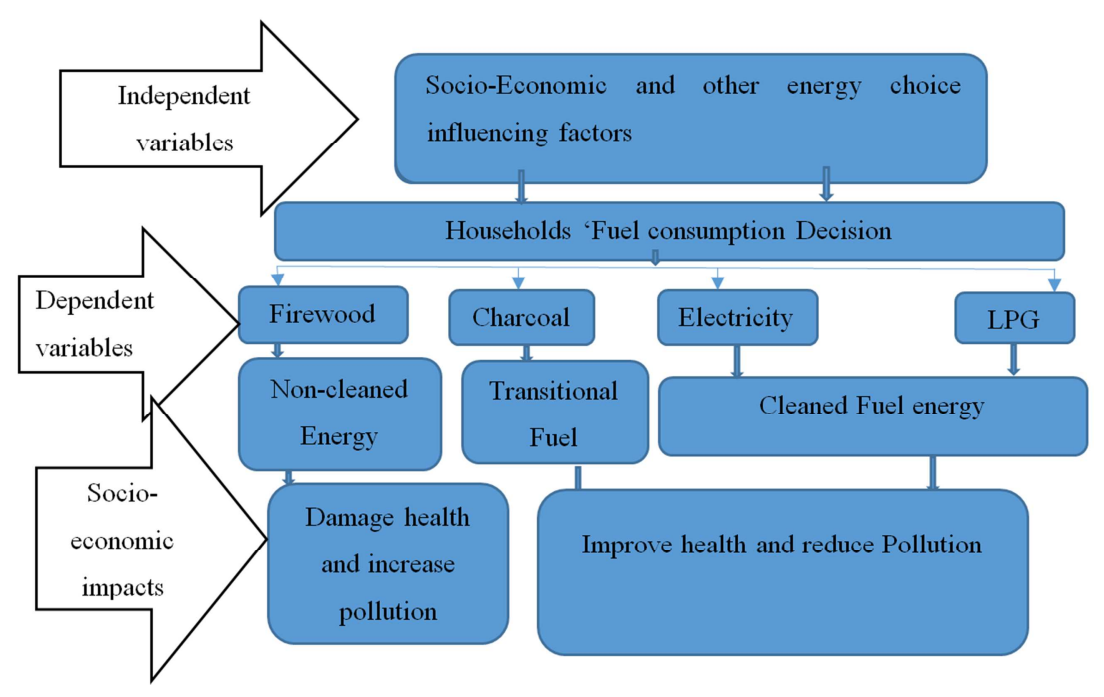

Source: Constructed by Personal author.

Figure 1. Framework for household's energy consumption decision and its implication.

\subsection{Model Specification}

The usage of logit versus probit models is heavily influenced by disciplinary traditions, while both probit and logit models could be used in the analysis, the logit model is widespread in econometrics especially econometric selection/choice model since the underlying utility could be understood as discrete outcome. Referring to the authors Jumbe and Angelsen [23] conducted the study in Malawi, in this analysis we utilized Multinomial logit model decision for displaying the household' choices among separated cooking fuels.

A family unit $\mathrm{n}$ chose among a bunch of totally unrelated fuel decisions, $j=1 \ldots, J$. The chief secures a specific degree of utility $U_{n j}$ from each substitute. The discrete decision model expands on the conviction that a family chooses the result that capitalize on utility. We don't watch household's utility, however watch a few qualities of the family which is defied by a choice to pick cooking fuel assortment. Subsequently, the utility is disintegrated into deterministic (expected utility which is assumed to be linear) $\varphi_{n}$ and random part:

$$
U_{n j}=\left(X_{i}, Z_{i j}\right)+\varphi_{i j}
$$

wit $\quad \varphi_{n j}=\alpha Z_{i j}+\beta_{j} X_{i+} \in_{i j}$, i i i i i i i $i \varphi_{i j}=\emptyset_{i j}+\epsilon_{i j}$

$X_{i}$ and $Z_{i j}$ deliver characteristics of the individual choice maker and characteristics of the substitutes in the choice set respectively. If $\alpha=0$, the model is multinomial logit (MNL).s the model may be referred to as a characteristic of chooser model, if $\beta_{j}=0$ the model is conditional logit and this may refer to as a characteristics of alternative model, if $\alpha=0$ and $\beta_{j}=0$ for all $\mathrm{j}$, then the resultant model is a mixed logit. The behavioral assumption underlying all three variants of the logit model is the same i.e., identically and independently distributed (iid) extreme value in a RUM model as referred to the authors Bourguignon et al. [24]. we determine the likelihood of a specific result. The stochastic part has a distribution $f($ ). The joint distribution for a vector of the stochastic part is meant as $f(n)$. To delineate family unit n's decision of substitute I on a scope of $\mathrm{J}$ substitutes, we use likelihood:

$$
\begin{gathered}
P_{n i}=\operatorname{Pr}\left(U_{n i}>, \forall j \neq i\right) \\
P_{n i}=\operatorname{Pr}\left(U_{n i}+{ }_{n i}>, \forall j \neq i\right) P_{n i}=\int I\left(U_{n i}+{ }_{n i}>U_{n j}+,\right. \\
\left.\forall j \neq i) \mathrm{~F}_{n}{ }_{n}\right) \mathrm{d}_{n}
\end{gathered}
$$

The multinomial logit model assumes independency of irrelevant alternatives (IIA) which implies that the ratio of the probabilities of deciding on any two options is independent of the other substitutes in the choice set. A variation of multinomial logit is settled logit model.

$$
\begin{gathered}
\left({ }_{n j}\right)=e^{-\varepsilon n j} e^{-e \varepsilon n j} \\
(n j)=e-e \varepsilon n j
\end{gathered}
$$

The likelihood that family unit $n$ decide on alternate $i$ amongst the $J$ another possibility of food preparation energy is assumed by the author McFadden [25];

$$
P_{n i}=\operatorname{Pr}\left(<\varphi_{n i}-\varphi_{n j}+{ }_{n i}, \forall j \neq i\right)
$$

$$
=\int \prod j \neq i \quad(U n i+n i>U n j+n j, \forall j \neq i) \quad() \mathrm{d} n i
$$

Thus, the choice probability is the integral over all values of $n i$ weighted by its density $\Lambda$ (.) as defined in equation (3). It is hypothesized that a person's decision of a viewpoint is 
controlled by a vector of socio-segment factors. This equation between vector of socio-segment actual attributes and the dependent variable is perceived by assessment vector of boundaries utilizing log-probability technique. Supposing each error term for all options $j$ is identically and independently distributed, the logit probability $\varphi n j+x_{n}{ }^{\prime} \beta_{j}$ that a particular household will choose alternative $j$ will be;

$$
P_{n i}=\frac{e\left(x_{n}^{\prime} \beta_{j}\right)}{\sum_{j} e\left(x_{n}^{\prime} \beta_{j}\right)}
$$

In the interim MNL is where regressors don't change over receptions, coefficients are assessed for any decision. The dependent variable is the cooking fuel decision (firewood, charcoal, generator, electricity and LPG) Holding the other indicator factors consistent, the normal coefficients give a level of the adjustment in the logit related with a unit change in the indicator variable. The dependent variable under this examination is the decisions of fuel for cooking in family units. As opposed to quantity of energy burns-through by family unit, it portrays the classifications of fuel utilized by family units.in this examination, we remember the accompanying arrangement of controls for our analysis: family unit income, size of the family unit; sorts of marriage inside family unit, level of education of household head, age of household head, type of habitant for households, location of the household, home ownership, total households non-energy expenditure.

\section{Results and Discussion}

\subsection{Data Description}

According to the results from above table 3, a wide contrast in the utilization of firewood and gas (LPG) can be seen among rural and urban households. In rural household, about 93.5 percent use firewood and just about 0.16 percent use gas (LPG), whereas in urban households just 37 percent use firewood and 3 percent as an example of a non-industrialized nation that has heavy reliance on tradition biomass fuel and a wide distinction in the utilization of modern fuel among rural and urban areas respectively in the figure 3 .

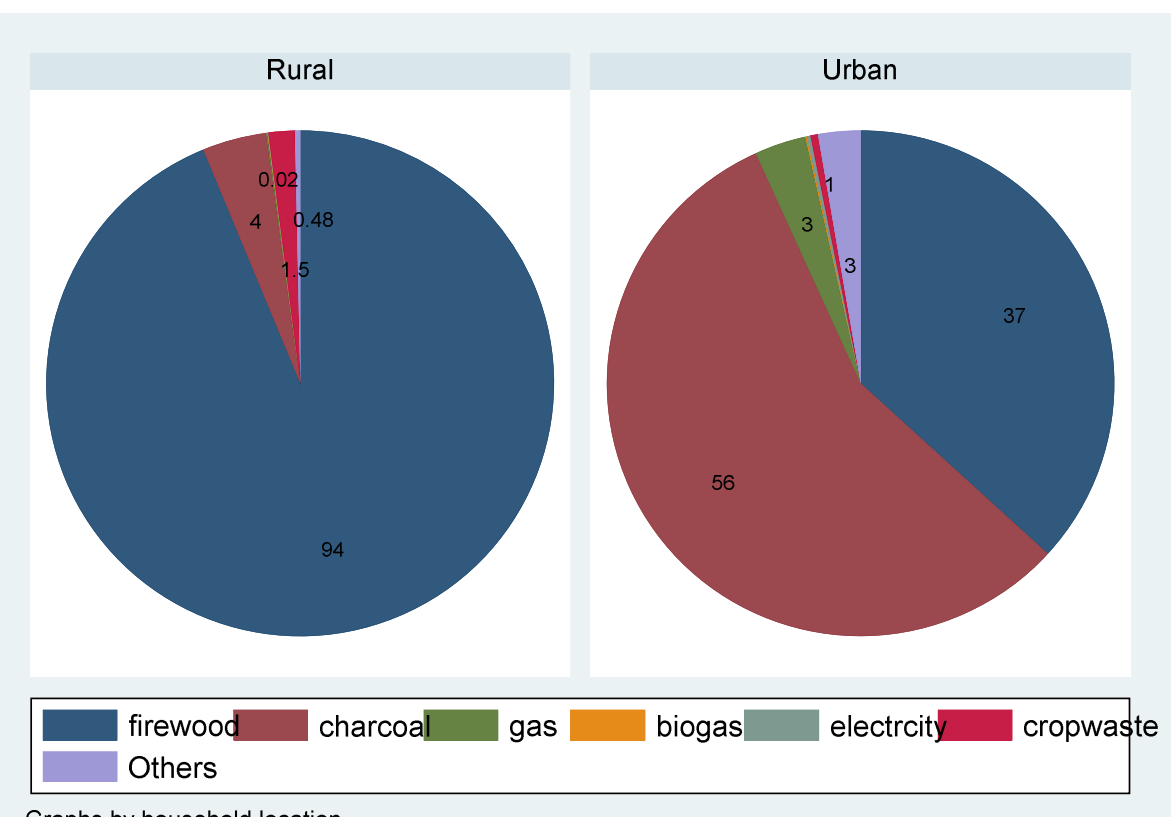

Graphs by household location

Source: Author's construction using all EICVs (2010-2011/ 2013-2014/2016-2017).

Figure 2. Household primary sources of cooking fuel energy by location.

Table 1. Household cooking energy expenditures by energy sources in region in all EICVs.

\begin{tabular}{llllll}
\hline $\begin{array}{l}\text { Primary source } \\
\text { of cooking fuel }\end{array}$ & \multicolumn{2}{l}{ household location } & & & \\
\cline { 2 - 6 } & rural & Percentage & urban & Percentage & Total \\
\hline Firewood & 22704 & 93.5 & 1720 & 37 & 84.55 \\
Charcoal & 994 & 4 & 2638 & 56 & 12.57 \\
LPG & 20 & 0.16 & 154 & 3 & 0.60 \\
Biogas & 6 & 0.02 & 3 & 0.3 & 0.03 \\
Electricity & 5 & 0.02 & 11 & 0.2 & 0.06 \\
crop waste & 407 & 2 & 23 & 0.5 & 1.49 \\
Others & 77 & 0.3 & 126 & 3 & 0.70 \\
Total & 24213 & 100 & 4675 & 100 & 100.00 \\
\hline
\end{tabular}

Source: Author's computed using all EICVs (2010-2011/ 2013-2014/2016-2017).
Table 2. Percentage change in using primary source of cooking fuel from 2010 to 2017.

\begin{tabular}{lllll}
\hline $\begin{array}{l}\text { Primary source } \\
\text { of cooking fuel }\end{array}$ & \multicolumn{4}{l}{ year of survey } \\
\cline { 2 - 5 } & $\mathbf{2 0 1 0}$ & $\mathbf{2 0 1 7}$ & Increase/decrease (\%) & Total \\
\hline Firewood & 12383 & 12041 & -2.76 & 24424 \\
Charcoal & 1479 & 2153 & 45.57 & 3632 \\
LPG & 11 & 163 & 1381.82 & 174 \\
Biogas & 4 & 5 & 25.00 & 9 \\
Electricity & 8 & 8 & 0.00 & 16 \\
cropwaste & 340 & 90 & -73.53 & 430 \\
Others & 83 & 120 & 44.58 & 203 \\
Total & 14308 & 14580 & & 28888 \\
\hline
\end{tabular}

Source: author's computed using all EICVs (2010-2011/ 2013-2014/20162017). 
From the figure 3 above is shown that rural households use firewood at 94 percent compared to the inner-city households with 37 percent while charcoal fuel was used at 4 percent in rural areas and 56 percent for urban areas LPG was use at 3 percent in urban areas while in rural areas was at 0.02 percent and other fuels like kerosene were use at 3 percent in urban areas whereas in rural areas were used at 0.48 percent, the crop waste fuels for cooking purposes were use at 1.5 percent in rural areas whereas in urban were used at 1 percent

From the table above showing the percentage change in primary source of cooking fuels used by households in different year of survey 2010 to 2017, It is shown that from 2010 to 2017 the households using firewood for cooking purposes decreased by 2.76 percent form 12,383 households using firewood in 2010 to 12,041 households using fire wood in 2017, also the households using charcoal increased by 45 percent and not surprisingly the households using gas for cooking purposes were increased by 138 .2percent from 2010 to 2017 .

From the above figure 4 , it is shown that southern province there were more household users for firewood at 93 per cent of the total cooking fuel energy used, households in Kigali city were more using charcoal at 68percent of the total cooking fuel energy used also Kigali city households were more users of gas(LPG) for cooking purposes at 5 percent of the total cooking fuel energy used in Kigali, households in the Eastern province were the most users of crop wastes fuel energy for cooking at 3 percent of the total cooking fuel energy used in the Eastern region.

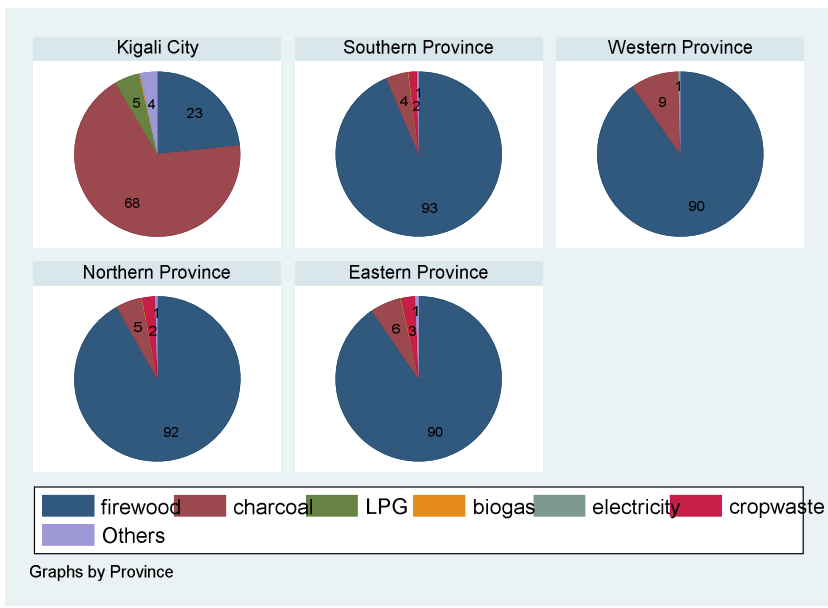

Source: Author's computed using all EICVs (2010-2011/ 2013-2014/2016-2017).

Figure 3. The associate of primary source of cooking fuel with Regional provinces.

\subsection{Analytical and Empirical Results}

From the figure 4 above which Showed the proportion of using total household income and energy expenditure, the smoothened yellow thick line local polynomial showed that energy expenditure for households raise with total income of the households with positive proportionality from 5units of energy expenditures and at confidence interval of 95 percent.

Table 3. Multinomial Logit Coefficients for Choice of Fuel for Cooking.

\begin{tabular}{|c|c|c|c|c|c|}
\hline VARIABLES & Charcoal & kerosene & LPG & Wood & generator \\
\hline \multirow[t]{2}{*}{ Total household income } & $4.201 *$ & $-3.583 * * *$ & 1.226 & -0.406 & $-415.4 * * *$ \\
\hline & -2.486 & -0.944 & -42.89 & -0.863 & -0.05 \\
\hline \multirow[t]{2}{*}{ Home ownership } & $-0.329 * * *$ & $0.0759 * *$ & $-0.404 *$ & 0.0212 & 0.039 \\
\hline & -0.0334 & -0.0339 & -0.225 & -0.0327 & -0.235 \\
\hline \multirow[t]{2}{*}{ Household size } & $0.0628 * * *$ & $0.0691 * * *$ & -0.065 & $0.0646 * * *$ & $0.0982 * * *$ \\
\hline & -0.00569 & -0.00562 & -0.0421 & -0.00546 & -0.0352 \\
\hline Type of marriage in household & -0.0491 & -0.0444 & -0.76 & -0.0445 & -0.274 \\
\hline \multirow[t]{2}{*}{ Household head type of education } & $1.679 * * *$ & $1.406 * * *$ & $-1.197 * * *$ & $1.469 * * *$ & $0.626^{* * *}$ \\
\hline & -0.0241 & -0.0237 & -0.246 & -0.023 & -0.154 \\
\hline \multirow[t]{2}{*}{ Age of household head } & $0.00271 * * *$ & $0.00844 * * *$ & -0.01 & $0.00930 * * *$ & 0.00387 \\
\hline & -0.000766 & -0.000766 & -0.00806 & -0.000743 & -0.00503 \\
\hline Type of habitant & $0.276^{* * *}$ & $0.0559 * * *$ & 0.0427 & $0.0580 * * *$ & -0.000365 \\
\hline \multirow[t]{2}{*}{ Household location } & $1.600 * * *$ & $0.245 * * *$ & $1.620 * * *$ & $0.151 * * *$ & -0.423 \\
\hline & -0.0395 & -0.0383 & -0.291 & -0.0371 & -0.314 \\
\hline \multirow[t]{2}{*}{ Non-energy expenditure of household } & $-4.503^{*}$ & $3.221 * * *$ & -0.357 & 0.122 & 415.2 \\
\hline & -2.486 & -0.943 & -42.88 & -0.862 & 0 \\
\hline \multirow[t]{2}{*}{ Constant } & $1.659 * * *$ & $2.054 * * *$ & $-17.73^{* * *}$ & $1.289 * * *$ & $-3.792 * * *$ \\
\hline & -0.105 & -0.105 & -0.788 & -0.101 & -0.679 \\
\hline Observations & 43,110 & 43,110 & 43,110 & 43,110 & 43,110 \\
\hline \multicolumn{6}{|l|}{ Notes Titles } \\
\hline \multicolumn{6}{|l|}{ Standard errors in parentheses } \\
\hline$* * * \mathrm{p}<0.01, * * \mathrm{p}<0.05, * \mathrm{p}<0.1$ & & & & & \\
\hline
\end{tabular}

Notes titles standard errors in parentheses *** $\mathrm{p}<0.01, * * \mathrm{p}<0.05, * \mathrm{p}<0.1$

Source: Author's computed using all EICVs (2010-2011/ 2013-2014/2016-2017). 


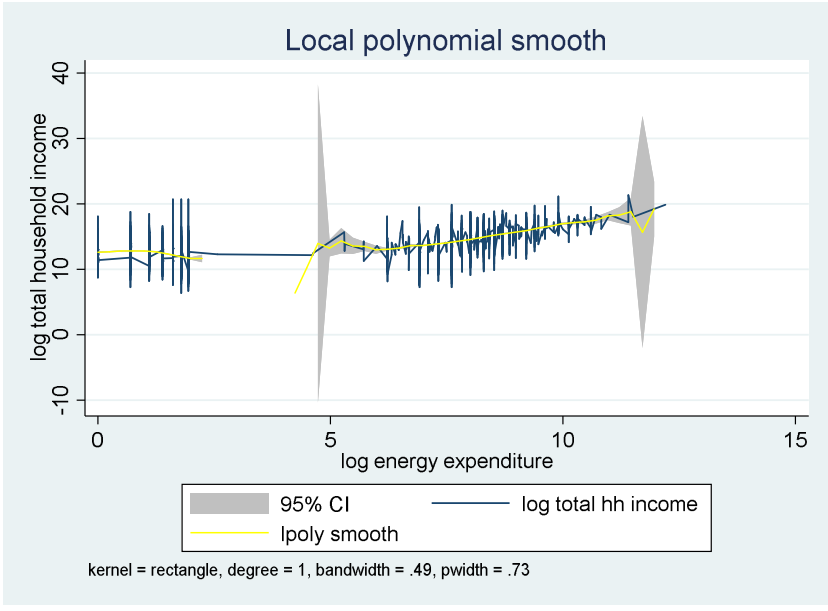

Figure 4. Household income and cooking energy expenditure relationship from 2010 to 2017.

Source: Author's construction using all EICVs (2010-2011/ 20132014/2016-2017).

Additional unit of income on households total income raise the likelihood for using charcoal and gas is increased by change factor of 4.2 and 1.226 respectively while decrease the likelihood of using kerosene and wood by change factor of 3.583 and 0.406 respectively. Polygamous headed households are less likely to use gas (LPG) by change factor of 0.429 while raising the likelihood of using charcoal, firewood and kerosene by change factor of $0.763,0.731$ and 0.67 probably because the Polygamous headed households are also economically requested more needs for the household members. Larger household size are more likely to use charcoal, kerosene, wood and generator by change factor of $0.0628,0.069$ and 0.065 respectively while reducing the likelihood for using gas(LPG) by change factor of 0.065 . The probable reason is that a larger household requires a higher quantity of fuel which may be difficult to meet by the use of expensive LPG; consequently, they depend more on cheaper biomass fuel. Compared with urban households and rural households, urban households are more likely to use gas (LPG) and charcoal by change factor of 1.620 and 1.60 respectively and positive likely to use wood and kerosene by change factor of 0.245 and 0.151 respectively. This may be related to the accessibility and affordability of gas (LPG) and charcoal which is much higher in urban areas than in rural areas.

Table 4. Effect of non-farm business (binary variable) in the Household's Choice of fuel for Cooking.

\begin{tabular}{llllll}
\hline Independent variable & wood & charcoal & kerosene & generator & LPG \\
\hline dummy for non-farm business & & & & & \\
Non-farm & 0.02 & $0.112^{* * *}$ & 0.03 & 0.00 & $0.672^{* *}$ \\
& -0.02 & -0.02 & -0.02 & -0.16 & -0.32 \\
\hline
\end{tabular}

Notes titles standard errors in parentheses $* * * \mathrm{p}<0.01, * * \mathrm{p}<0.05, * \mathrm{p}<0.1$

Source: Author's computed using all EICVs (2010-2011/ 2013-2014/2016-2017).

Table 5. Marginal effects Coefficients and Predicted probability of a Multinomial logit estimates (Base fuel choice $=$ wood).

\begin{tabular}{|c|c|c|c|c|c|c|c|c|c|c|}
\hline \multirow{2}{*}{ VARIABLES } & charcoal & Dy/Dx & kerosen & Dy/Dx & generator & Dy/Dx & Gaz & Dy/Dx & wood & Dy/Dx \\
\hline & \multicolumn{2}{|c|}{$\operatorname{pr}($ choice $=.41106497)$} & \multicolumn{2}{|c|}{$\operatorname{pr}($ choice $=.27897312)$} & \multicolumn{2}{|c|}{$\operatorname{pr}($ choice $=.25398688)$} & \multicolumn{2}{|c|}{$\operatorname{pr}($ choice $=.00030418)$} & \multicolumn{2}{|c|}{$\operatorname{pr}($ choice $=.32245866)$} \\
\hline \multirow[t]{2}{*}{ Lnincome } & 3.540 & 0.631 & $-3.635 * * *$ & $-0.650 * * *$ & $-415.4 * * *$ & $-1.781 * * *$ & 1.227 & 0.004 & -0.473 & -0.090 \\
\hline & -2.409 & -0.429 & -0.950 & -0.170 & -0.050 & -0.129 & -42.900 & -0.123 & -0.852 & -0.162 \\
\hline \multirow[t]{2}{*}{ Homeowner } & $-0.330 * * *$ & $-0.0587 * * *$ & $0.0758 * *$ & $0.0136^{* *}$ & 0.039 & 0.000 & $-0.404 *$ & $-0.00115^{*}$ & 0.021 & 0.004 \\
\hline & -0.033 & -0.006 & -0.034 & -0.006 & -0.235 & -0.001 & -0.225 & -0.001 & -0.033 & -0.006 \\
\hline \multirow[t]{2}{*}{ Hhsize } & $0.0628 * * *$ & $0.0112 * * *$ & $0.0691 * * *$ & $0.0124 * * *$ & $0.0982 * * *$ & $0.000421 * * *$ & -0.065 & 0.000 & $0.0646^{* * *}$ & $0.0123 * * *$ \\
\hline & -0.006 & -0.001 & -0.006 & -0.001 & -0.035 & 0.000 & -0.042 & 0.000 & -0.005 & -0.001 \\
\hline Polygamous & -0.049 & -0.009 & -0.044 & -0.008 & -0.274 & -0.001 & -0.760 & -0.002 & -0.045 & -0.008 \\
\hline \multirow[t]{2}{*}{ basic_educ } & $1.679 * * *$ & $0.299 * * *$ & $1.406 * * *$ & $0.252 * * *$ & $0.626 * * *$ & $0.00268 * * *$ & $-1.197 * * *$ & $-0.00342 * * *$ & $1.469 * * *$ & $0.279 * * *$ \\
\hline & -0.024 & -0.003 & -0.024 & -0.004 & -0.154 & -0.001 & -0.246 & -0.001 & -0.023 & -0.004 \\
\hline \multirow[t]{2}{*}{ Agehhd } & $0.00271 * * *$ & $0.000482 * * *$ & $0.00844 * * *$ & $0.00151^{* * *}$ & 0.004 & 0.000 & -0.010 & 0.000 & $0.00930 * * *$ & $0.00177^{* * * *}$ \\
\hline & -0.001 & 0.000 & -0.001 & 0.000 & -0.005 & 0.000 & -0.008 & 0.000 & -0.001 & 0.000 \\
\hline \multirow[t]{2}{*}{ Typhbt } & $0.276 * * *$ & $0.0492 * * *$ & $0.0559 * * *$ & $0.0100 * * *$ & 0.000 & 0.000 & 0.043 & 0.000 & $0.0581 * * *$ & $0.0110 * * *$ \\
\hline & -0.008 & -0.001 & -0.008 & -0.001 & -0.057 & 0.000 & -0.052 & 0.000 & -0.008 & -0.002 \\
\hline Inner-city & -0.040 & -0.007 & -0.038 & -0.007 & -0.314 & -0.001 & -0.291 & -0.001 & -0.037 & -0.007 \\
\hline \multirow[t]{2}{*}{ Lnnonenergy } & -3.842 & -0.684 & $3.273 * * *$ & $0.586 * * *$ & 415.200 & $1.781 * * *$ & -0.358 & -0.001 & 0.190 & 0.036 \\
\hline & -2.408 & -0.429 & -0.949 & -0.170 & 0.000 & -0.129 & -42.890 & -0.123 & -0.851 & -0.162 \\
\hline \multirow[t]{2}{*}{ Constant } & $1.674 * * *$ & & $2.054 * * *$ & & $-3.792 * * *$ & & $-17.73 * * *$ & & $1.290 * * *$ & \\
\hline & -0.104 & & -0.105 & & -0.679 & & -0.788 & & -0.101 & \\
\hline Observations & 43,110 & 43,110 & 43,110 & 43,110 & 43,110 & 43,110 & 43,110 & 43,110 & 43,110 & 43,110 \\
\hline $\begin{array}{l}\text { Standard errors } \\
* * * \mathrm{p}<0.01, * *\end{array}$ & in parenthes & & & & & & & & & \\
\hline
\end{tabular}

Notes titles standard errors in parentheses $* * * \mathrm{p}<0.01, * * \mathrm{p}<0.05, * \mathrm{p}<0.1$

Source: Author's computed using all EICVs (2010-2011/ 2013-2014/2016-2017). 
Sometime the households without other activities different from farming activities they usually made choice of cooking energy fuels different from the choice sometimes made by the households with only farming activities which rely mostly on the traditional cooking energy fuels as a result of the fuels accessibility for instance. Then in this study we would like to include the control dummy variable which is equal to unit if the household have other non-farm activities and zero otherwise. The results (table 4) showed that in comparison to farm business, non-farm business households are more likely to use Gas (LPG) by change factor of 67.2 percent in place of other cooking fuel energy while the households with non-farm business are more likely to use the charcoal by change factor of 11.2 percent compared to the households without non-farm businesses.

From the table 5, above it showed the marginal analysis for cooking fuel energy, it is shown that additional percentage rise in total households income is associated with an increase in in the predicted probability of using charcoal and gas by $63.1 \%$ and $0.4 \%$ respectively. Also the additional percentage rise in Polygamy for household heads is associated with an increase in in the predicted probability of using charcoal, firewood and kerosene by $13.6 \%, 13.9 \%$ and $11.9 \%$ respectively. As expected, the additional percentage rise in household size of members is associated with an increase in in the predicted probability of using charcoal, kerosene, wood by $1.12 \%, 1.24 \%$ and $1.23 \%$ respectively. Not surprisingly, the additional percentage rise in households living in urban areas is associated with an increase in in the predicted probability of using gas (LPG) and charcoal by $0.463 \%$ and $28.5 \%$ respectively.

\section{Conclusions and Policy Implication}

The study revealed that there was the higher dependency on biomass cooking energy fuels among Rwandan households with 84.55 percent for firewood usage and 12 percent for charcoal usage for cooking purposes. The socioeconomic attributes in inducing household's choice for cooking energy fuels have been identified. These include households' income, household location, age of household head, non-energy expenditures, number and composition of the members in households, type of habitant through different settlement means, whether the household live in their own homes or rented homes.

There is straight relationship between household's nonenergy expenditure with house household cooking energy source choice. Although there was significant decline in the proportion of the household using biomass energy sources for cooking purposes between 2010 and 2017 the total number of households using the charcoal energy for cooking purposes were decreased by 84.2 percent from wave1(2010/2011) to wave2(2013/2014) while 81 percent were a decrease from wave1(2010/2011) to wave3(2016/2017), the total number of households using wood fuels energy for cooking purposes were decreased by
89.1 percent from wave1(2010/2011) to wave2(2013/2014) while 83.1 percent were a decrease from wave1(2010/2011) to wave3(2016/2017), the condition seems to be persistent requiring energy sector targeted policies for taking care about this problem through introduction of other cleaner modern cooking energy fuels.

Taking into consideration of high demand for biomass cooking energy fuels especially for firewood and charcoal and yet the regeneration rate for wood is very low hence the high depletion rate resulted from the high pressure under the forest resources. To ensure the forest resources conservation, an intervention is required to reduce the high dependency for wood cooking energy fuels. The successful intervention would address the cost of energy and other consequences like health problems and environmental issues resulted from highly relying on wood cooking fuels. It is difficult to replace trees/forest for climate change mitigations at the desired pace for our country while it is possible to shift the household from traditional cooking energy fuels to clean modern cooking energy fuels.

i. Therefore this study suggests the need of the urgent and deliberated energy for cooking policies interventions for the households to switch to clean modern cooking energy fuels from traditional cooking energy fuels especially wood fuels and hence decreased impact of cooking energy fuels in the country.

ii. The government should not only increase the overall electrification rate within the country since the study showed that households living in inner-city areas are likely to use the clean modern cooking energy fuels but also improve the settlement means within the country since the study revealed that type of habitant for households influence the households' cooking energy fuels choice.

iii. The energy companies within the country should improve the training programs about the cleaner modern cooking energy uses without relying only on the formal education for the households' heads as the study surprisingly showed that household head with formal education were likely to use charcoal and wood fuels while were expected to be more likely to shift to cleaner modern cooking energy fuels instead.

iv. The households should encourage the family member to carry out some of non-farm income generating businesses for raising the total household income since the study showed that households with higher income were more likely to use cleaner modern cooking energy fuels.

v. The government should improve the energy policy that involves the measures for removing the constraints on the supply side of the LPG fuels for easy accessibility

\section{Conflict of Interest}

The authors declare that they have no competing interests. 


\section{References}

[1] Arowosoge, O. G. E \& Faleyimu, "Assessment of Household Energy Utilized for Cooking in Ado-Ekiti Metropolitan Area of Ekiti State, Nigeria," International Journal of Academic Research, pp. 3(151-155, 2011.

[2] United Nations, "policy brief in support of the high level political forum 2020: Accelerating SDG7 achievement in time of Covid19," Uinited Nations, 2020.

[3] WHO, "Interventions to reduce indoor air pollution avialble: http://www.who.int/indoorair/interventions/en/. accessed 23 Dec 2020,”WHO, 2017.

[4] Rehfuess EA, Puzzolo E, Stanistreet D, Pope D, Bruce NG, "Enablers and barriers to large scale uptake of improved solid fuel stoves:a systematic review.," Environ Health Perspect 122, pp. 120-130, 2014.

[5] H. Ladislas, "The transition from cooking with charcoal to LPG gas in Rwanda(2018-2024)," intergovermental research and policy journal, 2019.

[6] B. Malinski, “"Impact Assessment of Chitetezo Mbaula, Improved Household Firewood Stove in Rural Malawi",," GTZ. Probec., 2008.

[7] EICV5, NISR, "Rwanda Poverty Profile Report," EICV5, NISR, Kigali, 2016-2017.

[8] X. Zhang and S. Hassen, "Household fuel choice in urban China: A random effect generalized probit analysis," Journal of Business and Social Sciences Research, 2014.

[9] Alem, Y., Beyene, A. D., Köhlin, G., \& Mekonnen, A., "Household Fuel Choice in Urban Ethiopia: A Random Effects Multinomial Logit Analysis.," Environment for Development, 2013.

[10] Reddy, B. S., "“A multilogit model for fuel shifts in the domestic sector,", Energy 20, p. 929-936., 2015.

[11] R. Heltberg, "“Factors determining household fuel choice in Guatemala," Environment and Development Economics 10, p. 337-361, 2015.

[12] Alam, M., J. Sathaye, and D. Barnes, "Urban household energy use in India:efficiency and policy implications'," Energy Policy 26, p. 885-891, 2008.
[13] Chambwera, M., Folmer, H.,, "“Fuel switching in Harare: An almost ideal demand system approach"," Energy Policy, 35, pp. 2538-2548, 2007 ..

[14] Saad. S, Bugaje, "Biomass consumption in Nigeri a: Trends and policy issues.," Journal of Agriculture and Sustainability. 9 (2):; pp. 127- 157, 2016.

[15] Farsi, M., Filippini, M., Pachauri, S., "“Fuel choices in urban India households"," Environment and Development Economics, 12, pp. 757-774, 2008.

[16] Gangopadhyay, S., B. Ramaswami, and W. Wadhwa, “'Access of the poor to modern household fuels in India'," SERFA Report for the World Bank, washington DC, 2003.

[17] B. Ouedraogo, “"Household energy preferences for cooking in urban Ouagadougou, Burkina Faso"," Energy Policy, Vol. 34 No. 18, p. 3787-3795, 2006.

[18] Koswari, R., \& Zerriffi, H., "Three-dimensional energy profile: A conceptual framework for assessing household energy use.," Energy Policy, 39 (12), p. 7505-7517, 2011.

[19] van der Kroon B, Brouwer R and van Beukering PJH, "The energy ladder: theoretical myth or empirical truth? Results from a meta-analysis.," Renew Sustain Energy Rev 2013; 20, p. 504-513., 2013.

[20] Rahut, D. B., Behera, B., \& Ali, A., "Determinants of household energy use in Bhutan.," Energy, 69 (May), p. 661672., 2014.

[21] A. Wickramasinghe, ""Energy access and transition to cleaner cooking fuels and technologies in SriLanka: Issues and policy limitations"," Energy Policy, Vol. 39 No. 12, p. 7567-7574., 2011.

[22] Ezzati, M. and D. M. Kammen, "'Evaluating the health benefits of transitions in household energy technologies in Kenya'," Energy Policy 30, p. 815-826., 2010.

[23] Jumbe, C. B.; Angelsen, A., "Modeling choice of fuelwood source among rural households in Malawi: A multinomial probit analysis.," Energy Econ. 2011,, pp. 33, 732-738., 2011.

[24] Bourguignon, F., Fournier, M., Gurgand, M.,, “" "Selection Bias Corrections Based on the Multinomial Logit Model: Monte-Carlo Comparisons"," Journal of Economic Surveys, 21(1), pp. 174-205., 2007.

[25] D. McFadden, ""Conditional logit analysis of qualitative choice behaviour", in P. Zarembka (Ed.)," Frontiers in Econometrics, Academic Press, New York, p. 105-142, 2008. 